\title{
Moral agency and spirituality in palliative care
}

\author{
Francisca Rego, Guilhermina Rego, Rui Nunes \\ Faculty of Medicine of the University of Porto, Porto, Portugal \\ Contributions: (I) Conception and design: All authors; (II) Administrative support: F Rego; (III) Provision of study materials or patients: All authors; \\ (IV) Collection and assembly of data: All authors; (V) Data analysis and interpretation: All authors; (VI) Manuscript writing: All authors; (VII) Final \\ approval of manuscript: All authors. \\ Correspondence to: Francisca Rego, PhD. Faculty of Medicine of the University of Porto, Alameda Prof. Hernâni Monteiro, 4200-319, Porto, Portugal. \\ Email: mfrego@med.up.pt.
}

\begin{abstract}
Moral agency is a prerequisite for a full autonomous decision, meaning that the agents have the intrinsic capacity to understand their actions and to be accountable for the consequences of these actions. Palliative care patients have the moral right to build their capacity to decide, so that they are truly empowered to make choices. However, moral and spiritual distress are common at the end-of-life, which may arise if there is a threat to the individual's integrity and disruption of one's belief system, consequently leading to the deterioration of the patient's moral agency. The aim of this paper is to determine if spirituality may be an important tool for the empowerment of palliative care patients and if moral agency can be enhanced by a diligent spiritual advocate. Spiritual awareness, self-knowledge, and specific training are key elements for the spiritual advocate to address patients' spiritual needs and distress in a neutral and non-directive way, to promote autonomy, well-being, and quality of life. Thus, patients' dignity and right for self-determination are respected, thereby supporting empowerment, reducing suffering, respecting patients' individuality, and engaging moral agency. Palliative care patients should be able to fully exercise their autonomy. This strategy might be very appealing for adequate advance care planning, whatever the choices of the patient, as well as to prevent distress, hopelessness, and the lack of meaning that many terminal patients experience.
\end{abstract}

Keywords: Autonomy; empowerment; moral agency; palliative care; spirituality; terminal patient

Submitted Oct 31 2019. Accepted for publication Feb 142020.

doi: $10.21037 /$ apm-19-436

View this article at: http://dx.doi.org/10.21037/apm-19-436

\section{Introduction}

Palliative care patients' exercise of autonomy is important for a clinical practice that is based on universal ethical principles. Thus, it is important to determine to what extent these patients are actually able to fully exercise their autonomy, and how it can be optimized. Patient autonomy is usually compromised at the end-of-life because there are intrinsic and external circumstances that may deeply affect a patient's true autonomous decision. It follows that any strategy that may develop the patients' decision-making skills should be thoroughly considered in the healthcare setting.

Thus, the enhancement of autonomy at the end-oflife is even more compelling because individual choices and decisions are particularly complex, which results from the nature of the problems and their potential consequences. Thus, it is essential to ensure that the patient has the opportunity to choose, notwithstanding the fact that palliative care patients are usually overwhelmed by the disease and all the personal, familial, and social consequences involving palliative care.

The aim of this paper is to determine if spirituality may be an important tool for the empowerment of the palliative care patient and if moral agency can be enhanced by a diligent spiritual advocate.

\section{Moral agency and full personhood}

In clinical practice, respect for personal autonomy, as 
respect for persons in general, has progressively been considered to be a milestone. However, to accomplish autonomy, one must be a free moral agent because to be a person in the philosophical sense depends on being a moral agent. Moral agency is a prerequisite for a full autonomous decision, meaning that the agents have the intrinsic capacity to understand the full scope of their actions and to be accountable for the consequences of these actions or omissions. A moral agent is a person in the moral sense, someone who may have a moral call and who is expected to act accordingly.

A moral agent is the bearer of moral rights and duties (1). When humans acquired a symbolic culture and a symbolic representation of words, ideograms, or grammatical organization, they became ontologically differentiated from other species that do not manifest those abilities. This is, the evolution of the mind more than of the brain was the ontological jump and the phylogenetic mark (2). Rationality is enough to identify a human personality, but a human being can exist even without being rational. The human being is the material support of the person; that is, through evolution, the person is permanently enriching their ability for self-recognition until they are self-aware of that selfrecognition. Here, the human person begins to structure him- or herself through the memorization process of the symbolic external culture and its reinvention, which ends only with dementia or death.

Therefore, the distinction between human life (in general), the life of a specific human being and the life of a full human person is paramount (3). Currently, only competent humans are considered to be true moral agents. Incompetent humans, such as newborns, children, or adults with a specific incapacity (cognitive and/or emotional incompetency) lack moral agency because of the incapacity to deliberate autonomously (4). However, and despite recent developments in artificial intelligence, it will also be difficult to suggest that even a futuristic combination of hard and software computerized capacities can ever achieve a true moral agency, acknowledging that the concept of life itself might have to be revisited $(5,6)$.

It follows that personhood is a continuous process and progressiveness is the landmark of becoming a full autonomous person. Progressiveness in the development of certain properties/capacities is usually considered to be the core of personhood, namely consciousness and selfconsciousness, preferences, thoughts, conscious desires, feelings, sense of time, rational thought, unification of desires over time, and rational deliberation. Similarly, the capacity to experience pleasure and pain, to remember one's past actions and mental states, to envisage a future for one's self, to interact and communicate socially, to have long-term interests, and to take moral considerations into account in moral choices seem to be inherent to the concept of moral agency (7). To be a person in the philosophical sense, there are some indicators of human personhood that must be present and recognized: self-consciousness, selfrepresentation, rationality, abstract thinking, self-control, sense of the past and future, capacity of intentionally establishing relationships, and moral sense.

However, it might be rather difficult to ascertain that a particular human being is only considered to be a moral agent if he/she is in active possession of all these characteristics because different persons exhibit different characteristics in very different contexts. Thus, it follows that detectable evidence of personhood is a key element to determine which individuals have moral agency. Nevertheless, beyond the presence or absence of this large set of characteristics, the capacity to value one's own existence is paramount for assigning personhood and moral agency (8). True moral agents are responsible for their actions and have an implicit duty to cause good (to other people, to society, or to the environment), or at least not to cause unjustified harm (9), and to live life as autonomous and responsible agents, in conformity with their cognitive, emotional, and social skills. Thus, competence, information, liberty, and accountability are the variables that integrate this ethical puzzle. James Rachels states quite clearly that "for Kant, treating someone as an end-in-himself means treating him as a rational being. Thus, we have to ask, what does it mean to treat someone as a rational being? Now a rational being is someone who is capable of reasoning about his conduct and who freely decides what he will do, on the basis of his own conception of what is best. Because he has these capacities, a rational being is responsible for his actions" (10). Additionally, from a social perspective, the moral agent must also have a sense of justice (11), meaning that in a context of a well-organized and structured society that enables everyone the access to basic goods, the moral personality is also at the core of equality.

William Rottschaefer, in the interface between moral and psychological agency, goes further and suggests that there are two-tiered models of human agency, according to which "agents have at least two motivational systems. The first, a lower-level system, whose basic causal factors are a set of first-level beliefs and desires, has as its function the motivation of behaviors. The second system, a meta- 
level system, is made up of a set of second-level beliefs and desires about the first level beliefs and desires... Moral agency, and not merely human agency, is exercised when the determinative second-level beliefs and desires are moral ones" (12). This means that moral agency can be cognitively motivated and influenced by an external set of rules and principles and, therefore, relative and contingent to a particular set of beliefs. Indeed, we live in a plural world where different conceptions of "what's good" coexist. And, these conceptions are related to the beliefs developed in a particular cultural environment. Still, there is also an inner focus on where the acts of human beings come from: the interiority of the acts, which become the supreme characteristic of moral agency and not merely an instrumental act. This perspective of "interiority" is related, on the one hand, to the intention and motivation of the moral agents, and, on the other hand, it is related to the structural basis of their decisions.

Thus, moral agency is an essential characteristic of a full human person and a determinant factor to be a member of the moral community, thus allowing the agent to play a role in the core of moral life (13). However, taking into consideration this plethora of capacities, it might be asked if any of them are to be taken as more significant than the others? If so, which ones, and why? Tristram Engelhardt Jr. tries to answer this question, stating that "these three characteristics of self-consciousness, rationality, and moral sense identify those entities capable of moral discourse. These characteristics give to those entities the rights and obligations of the morality of self-respect. The principle of autonomy and its elaboration in the morality of mutual respect applies only to autonomous beings. It concerns only persons. The morality of autonomy is the morality of persons" (14).

\section{Spiritual distress and autonomy in palliative care}

From a decisional perspective, a fully mentally intact person presupposes at least two conditions: rationality and emotional balance (15). That is, for someone to decide properly and in accordance with one's own will, all forms of cognitive impairment should be detected and addressed. For example, a patient's will must not be subjected to any kind of manipulation, namely expressed or implicit forms of coercion. Additionally, patients must not be unduly influenced by pain or other physical or psychological distress, so that their capacity to make sound judgment is guaranteed. Thus, emotional distress and all forms of affective conditions should also be addressed and clinically managed (e.g., depression).

Morally, the concept of a person requires consensus over the expected psychological integrity of the moral agent (16). Thus, the person is a single entity with a single identity, and this continuity, even in circumstances of diminished awareness (such as sleep or the influence of sedative drugs), implies an established unity because the person is the same although in constant recreation in and out of himor herself. In the late stages of dementia, there might exist some discontinuity of the personality. Nevertheless, it will be difficult to argue that a person is "dead" by discontinuity of the personality and that a "new person" has steadily developed because some residual aspects of the personality, namely inferences from past memories, are likely to be present forever, regardless of the exterior behavior of the demented patient.

An autonomous decision presupposes the capacity to decide and, although moral agency is an absolute condition, only a minimal cognitive awareness is necessary for an agent to be considered autonomous. An agent might even develop progressively his/her capacity, so that connectedness is enhanced. Therefore, if having moral agency is linked to interests that must be protected, it might be assumed that palliative care patients have the moral right to build their capacity to decide (although the capacity to decide is often a limitation of the illness). So, it is essential that the patient feels truly empowered to make choices in the most autonomous way possible. Thus, the question should be: how it is possible to leverage autonomy at the end-oflife and what is the role of healthcare professionals in this setting?

Patients perceive and experience illness, care, and death according to their culture, values, beliefs, life experiences, and meaning of life. Thus, it can be argued that spirituality plays a key role because it is defined as a journey of selfdiscovery and a search for the sacred, for the meaning, and for the purpose of life (17). Spirituality may be perceived as existential or religious, and it can be defined by individuals seeking and expressing meaning and purpose and the way they experience their connectedness to the moment, to [the] self, to others, to nature, and to the significant or sacred (18-20). It is considered to be unique in each individual and it plays an important role at the end-of-life because spiritual well-being is associated with higher rates of social support and quality of life, better preparedness for the endof-life, and physical and psychological well-being $(21,22)$. 
According to the literature, patients whose spiritual needs have been addressed have a better quality of life (23), and the promotion of patients' spiritual well-being and the development of a sense of meaning in life and peace within has shown benefits for improving mental health in palliative care (24).

Suffering is a common phenomenon in palliative care patients, which impacts all aspects of life and can threaten the agency of the patient. To address the patient as a whole, Saunders and Sykes developed the concept of total pain, which encompasses its physical, psychological, social, and spiritual dimensions. In this context, palliative care embraces a holistic, transcultural, comprehensive, and patient-centered approach, aiming to manage the patients' relational existence with all these dimensions $(25,26)$.

Spiritual distress is very common in life-threatening illnesses, and it is defined as the disruption of one's beliefs in their value system (27). It is modulated by various influences, including conflicts between beliefs and life events (28), no reference to the patient's will and its conflict with that of the family (23), and a lack of understanding of spiritual issues by health professionals (29). Unfortunately, spiritual care provided in various palliative care centers is mostly influenced by the religious backgrounds of patients and centers, resulting in poorly assessed and met spiritual needs, which impact patients' quality of life and satisfaction with care $(23,30)$. However, certain countries have adopted an eclectic, secular and multi-denominational approach of spiritual care, such as Canada, US, UK or The Netherlands (31). Spirituality and religion are not opposite concepts because they include the search for the sacred, but religion is considered to be an outward expression of a particular spiritual or faith system and it includes the search for social/ health identity and rituals to assist in this search for the sacred (32). However, it is important to distinguish between both concepts because spirituality is considered to be part of most patients' total existence and encompasses more than religion (22).

Although moral distress is commonly discussed among healthcare professions, moral distress in patients is also a type of suffering that arises in response to challenges/ threats to the individual's integrity (33), which can lead to the deterioration of one's moral integrity and possibly one's moral agency. For example, it can be triggered by the inability to modulate one's response to suffering or through conflicts with one's religious or spiritual beliefs $(34,35)$, resulting in physical (i.e., insomnia, fatigue), emotional (i.e., withdrawal, emotional exhaustion), behavioral (i.e., impaired thinking, avoidance), and spiritual (i.e., loss of sense of meaning, deterioration of moral agency) responses to moral distress (36-38).

It follows that spiritual distress, namely unbearable suffering, can seriously compromise autonomy at the endof-life. Moral agency may be affected and all efforts to empower willing patients should be considered. Even taking into consideration that it does not mean that everybody agrees with a particular choice of a rational agent.

\section{Spiritual advocacy and empowerment of the palliative care patient}

Palliative care patients are considered to be frail individuals, given their overall health condition, and thus, adequate care ethics should focus on the patient within a set of relationships because all of life's dimensions will play an important role in how end-of-life will be interpreted and experienced. Thus, to be inclusive and promote empowerment, one should encourage relationships that bond "powerless individuals to more powerful ones" (39). Kant suggests that when individuals of differing power are together, a mutually binding moral space is facilitated because social practice maintains reciprocity between them (40). Therefore, advocacy in palliative care is not about forcing autonomous decision-making onto vulnerable patients, but, rather, it is based on a moral process of interdependence because promoting advocacy and empowerment implicates determining and implementing what is important to the patient (39). It involves encouraging the patient to reflect about which needs and desires must be addressed and to engage in decision-making to enhance empowerment, wellbeing, and quality of life.

In this context, empowerment is a process that enables restoration of the sense of dignity, autonomy, and selfworth. Thus, healthcare professionals should become aware of the power that they exercise and the power that is exercised over them (41) because there is often an uneven power distribution in which the patient is more of a passive agent (42). Self-knowledge, spiritual awareness and specific training are key elements for healthcare professionals working in palliative care settings (43), as they are faced with different spiritual values, beliefs and experiences and also with death.

Patient empowerment is defined as "a process through which people gain greater control over decisions and actions affecting their health" (44). Thus, keeping the patient central in all decision-making, that is, respecting 
patient autonomy, is essential to ethical care for dying patients. Autonomy calls for the patient to engage in the decision-making process that is, having the right to selfdetermination (45).

Autonomy can be related to the capacity for decisionmaking as well as functional capacity (46). Palliative care patients' decision-making may be influenced by biological factors, such as the progression of the illness, delirium and dementia, as well as by cultural, spiritual, religious, and existential beliefs, expectations, values, experiences and the sense of personal meaning and satisfaction in life $(47,48)$.

Thus, for healthcare professionals to determine how patients prefer to be included in decision-making, cultural and spiritual and/or religious aspects of individuals need to be considered $(49,50)$. There is also a need to provide an environment in which these health beliefs and needs are discussed and integrated into the care plan, as well as to involve an advocate with special expertise in cross-cultural issues and spirituality, when appropriate $(20,50,51)$.

Therefore, the spiritual advocate is a healthcare professional with specific training who is prepared to address any patient's spiritual life needs and distress in a non-directive way (allowing the patient to share what he/ she desires) to promote autonomy, well-being, quality of life and an adequate quality care (52). The role of the advocate can be subsumed by any healthcare professional, and not necessarily by a new set of professionals. It is someone who goes beyond the usual barriers of professional practice to pursue a different level of attitudes. The advocate is central to moral agency by enabling an understanding of care goals and illness progression and by maintaining the patient's concerns central (53). Understanding moral agency requires looking at how people exercise their capacity to reflect on the moral purpose of their lives $(54,55)$, this way promoting patients' full moral agency.

Although the overall aim is to increase self-awareness and well-being of the patient, advocacy implies both a specific commitment as well as a general attitude towards the empowerment of the terminal patient. Advocacy and counselling, although specific, should be neutral in the sense that non-directiveness is the landmark of an adequate and proper advocacy, meaning that any form of hard and even soft paternalism is deemed unacceptable. It is acceptable that terminal patients in the course of palliative care or spiritual assistance delegate their deliberative capacity to other people, namely the assisting physician, nurse, or a family member. However, the impact of that participation must be kept to a minimum because surrogate decision makers can leave moral residues, such as making decisions influenced by their own values and principles (56).

Thus, the spiritual advocate has an obligation to address the singularity of the patient, maintain the individual's integrity, and promote empowerment and patient's moral agency, which is the ability to identify and embrace the guiding values of life, execute decisions, and develop traits that express those values. These traits were found to be linked to self-efficacy and autonomy, as well as predictive of improved health outcomes via treatment adherence, selfcare, hope, and the ability to cope (57). The individual's uniqueness elicits a moral obligation to live life according to its own inner nature, in which moral involvement and personhood are drawn from the meanings and significance of everyday experiences (58). Thus, as moral agents, the concern for what gives life meaning and the attempt to express it can change the patient's belief of what is good, thereby generating new possible meanings for personhood (58). In this manner, the spiritual advocate can achieve authenticity through empathy and by exploring the patient's inner potential, and still avoid external social and cultural influences by which one's nature might be compromised because each individual is the core of one's own moral world.

Thus, the spiritual advocate would focus on restoring and empowering the patient's moral agency by nonjudgmentally assessing and addressing the individual's needs, desires, and distress from a trans- and multi-disciplinary perspective, always taking into account the patient's cultural and ethical background, spiritual history, values, and beliefs, as well as promoting engagement on decisionmaking that integrates understanding, appreciation, and reconnection, to promote an appropriate response to the patient's needs and to the dying process $(57,59)$. In this manner, the person's dignity, right to self-determination and autonomy are respected, thereby supporting and promoting empowerment, reducing suffering, respecting the patient's individuality, and engaging moral agency.

Terminally ill patients are usually considered to be moral agents as long as they maintain awareness, rationality, and moral sense and so, their choices should be respected. Thus, considering a palliative care patient to be a moral agent and an autonomous person is essential for the process of obtaining informed consent, in both actual informed consent, such as authorization for a particular course of action namely in the palliative care context, as well as in 
prospective consent, i.e., a living will. This strategy might be very appealing for adequate advance care planning, whatever the choices of the terminal patient, i.e., symptom control, palliative sedation, or an advance directive to withhold or withdraw disproportionate treatments. For information to be integrated as a fundamental element in the decision-making process, the agent must be adequately empowered. Spirituality might be an important tool to many patients namely in a secular pluralistic society where very different moral perspectives come together in the healthcare setting.

\section{Conclusions}

Palliative care patients have an increasing life expectancy. Also, the demand for an early integration of patients in palliative care will possibly increase in the future. Thus, the full exercise of autonomy will also be progressively more substantial, bearing in mind that competence is a complex concept in which rationality must be mixed with emotional insights and human intuitions, which are essential variables in the moral decision-making process. The fact that people are living longer will raise certain ethical, social, and professional challenges in the future. It follows that the concept of the terminally ill patient may evolve for very different reasons, given the rapid progression of science and biotechnology (60). This demographic evolution is typically in accordance with a consensual longevity dividend, meaning that the increase in age of the population must be balanced with a better quality of life including the exercise of the right of self-determination at the end-of-life. On the one hand, there is a growing number of elderly people and, on the other hand, patients in palliative care will last much longer because of better healthcare as well as wider inclusion criteria.

These "ageing well societies" must also address the issue of including all people who are in very different conditions (61). In a multicultural world, with very different perspectives on how to accomplish a good life, terminally ill patients should have the fullest capacity to decide and to act according to their informed opinions. Even in the context of palliative care as well as euthanasia and assisted suicide (62), spiritual care may be a very resourceful tool.

Thus, spiritual advocacy by healthcare professionals may be an important tool to promote the empowerment, autonomy, and dignity of these patients, as well as to prevent hopelessness and the lack of meaning that are experienced by many palliative care patients.

\section{Acknowledgments}

We would like to thank Professor Harvey Max Chochinov, University of Manitoba, for his valuable recommendations. Funding: None.

\section{Footnote}

Conflicts of Interest: All authors have completed the ICMJE uniform disclosure form (available at http://dx.doi. org/10.21037/apm-19-436). The authors have no conflicts of interest to declare.

Ethical Statement: The authors are accountable for all aspects of the work in ensuring that questions related to the accuracy or integrity of any part of the work are appropriately investigated and resolved.

Open Access Statement: This is an Open Access article distributed in accordance with the Creative Commons Attribution-NonCommercial-NoDerivs 4.0 International License (CC BY-NC-ND 4.0), which permits the noncommercial replication and distribution of the article with the strict proviso that no changes or edits are made and the original work is properly cited (including links to both the formal publication through the relevant DOI and the license). See: https://creativecommons.org/licenses/by-nc-nd/4.0/.

\section{References}

1. Harris J, Holm S. Abortion. In: Lafollete H, editor. The Oxford Handbook of Practical Ethics. Oxford: Oxford University Press, 2003.

2. Donald $M$. Origins of the modern mind. Three stages in the evolution of culture and cognition. Cambridge: Harvard University Press, 1993.

3. Ford N. When did I begin? Conception of the human individual in history, philosophy and science. Cambridge: Cambridge University Press, 1988.

4. Giubilini A, Minerva F. After-birth abortion: Why should the baby live? J Med Ethics 2013;39:261-3.

5. Jonas H. The phenomenon of life: Toward a philosophical biology. Chicago: The University of Chicago Press, 1982.

6. Johnson C. Life: Definitions. In: ten Have H, editor. Encyclopedia of global bioethics. Berlin: Springer, 2016.

7. Tooley M. Personhood. In: Kuhse H, Singer P, editors. A companion to bioethics, Blackwell Companions to Philosophy. Oxford: Blackwell Publishers, 1998. 
8. Harris J. The value of life. An introduction to medical ethics. London: Routledge, 1991.

9. Beauchamp T, Childress J. Principles of biomedical ethics. 7th edition. New York: Oxford University Press, 2012.

10. Rachels J. The elements of moral philosophy. 3rd edition. Boston: McGraw-Hill College, 1999.

11. Rawls J. A theory of justice. New York: Harvard University Press, 1971.

12. Rottschaefer $W$. The biology and psychology of moral agency. Cambridge studies in philosophy and biology. Cambridge: Cambridge University Press, 1998.

13. Pessina A. Person. In: ten Have H, editor. Encyclopedia of global bioethics. Berlin: Springer, 2016.

14. Engelhardt T. The foundations of bioethics. 2nd edition. New York: Oxford University Press, 1996.

15. McAdams D. The moral personality. In: Narvaez D, Lapsley DK, editors. Personality, identity and character: Explorations in moral psychology. New York: Cambridge University Press, 2009.

16. McAdams D. The art and science of personality development. New York: Guilford Press, 2015.

17. Koenig H, McCullough M, Larson D. Handbook of religion and health. New York: Oxford University Press, 2001.

18. Best M, Butow P, Olver I. The doctor's role in helping dying patients with cancer achieve peace: A qualitative study. Palliat Med 2014;28:1139-45.

19. Asgeirsdottir GH, Sigurbjornsson E, Traustadottir R, et al. In the shadow of death: existential and spiritual concerns among persons receiving palliative care. J Pastoral Care Counsel 2014;68:4.

20. Puchalski C, Ferrel B, Viriani R, et al. Improving the quality of spiritual care as a dimension of palliative care: the report of the consensus conference. J Palliat Med 2009;12:885-904.

21. Bennett KS, Shepherd J. Depression in Australian women: The varied roles of spirituality and social support. J Health Psychol 2013;18:429-38.

22. Edwards A, Pang N, Shiu V, Chan C. The understanding of spirituality and the potential role of spiritual care in end-of-life and palliative care: A meta-study of qualitative research. Palliat Med 2010;24:753-70.

23. Kang J, Shin DW, Choi JY, et al. Addressing the religious and spiritual needs of dying patients by healthcare staff in Korea: Patient perspectives in a multi-religious Asian country. Psychooncology 2012;21:374-81.

24. Mystakidou K, Tsilika E, Parpa E, et al. Demographic and clinical predictors of spirituality in advanced cancer patients: A randomized control study. J Clin Nurs 2008; 17:1779-85.

25. Saunders C, Sykes N. The management of terminal malignant disease. 3rd edition. London: Edward Arnold, 1993.

26. Sulmasy DP. A biopsychosocial-spiritual model for the care of patients at the end of life. Gerontologist 2002;42:24-33.

27. Richardson P. Spirituality, religion and palliative care. Ann Palliat Med 2014;3:150-9.

28. Anandarajah G, Hight E. Spirituality and medical practice: Using the HOPE questions as a practical tool for spiritual assessment. Am Fam Physician 2001;63:81-9.

29. Murray SA, Kendall M, Grant E, et al. Patterns of Social, Psychological, and Spiritual Decline Toward the End of Life in Lung Cancer and Heart Failure. J Pain Symptom Manage 2007;34:393-402.

30. Clark PA, Drain M, Malone M. Addressing patients' emotional and spiritual needs. Jt Comm J Qual Saf 2003;29:659-70.

31. Gijsberts MHE, Liefbroer AI, Otten R, et al. Spiritual Care in Palliative Care: A Systematic Review of the Recent European Literature. Med Sci (Basel) 2019;7:25.

32. Emmons RA, Paloutzian R. The psychology of religion. Annu Rev Psychol 2003;54:377-402.

33. Thomas TA, McCullough L. A philosophical taxonomy of ethically significant moral distress. J Med Philos 2015;40:102-20.

34. Rushton CH, Kaszniak A, Halifax J. A framework for understanding moral dis-tress among palliative care clinicians. J Palliat Med 2013;16:1074-9.

35. Davis S, Schrader V, Belcheir M. Influencers of ethical beliefs and the impact on moral distress and conscientious objection. Nurs Ethics 2012;19:738-49.

36. Musto LC, Rodney PA, Vanderheide R. Toward interventions to address moral distress: navigating structure and agency. Nurs Ethics 2015;22:91-102.

37. McCarthy J, Gastmans C. Moral distress: a review of the argument-based nursing ethics literature. Nurs Ethics 2015;22:131-52.

38. Rushton CH, Caldwell B, Kurtz M. Moral distress: a catalyst in building moral resilience. Am J Nurs 2016;116:40-9.

39. Webb P. Ethical issues in palliative care. 2 nd edition. Oxford: Radcliffe Publishing, 2005.

40. Kant I. The Metaphysics of morals. Part 2. The doctrine of virtue. Gregor M, editor. New York: Cambridge University Press, 1991.

41. Martin G. Empowerment of dying patients: the 
strategies and barriers to patient autonomy. J Adv Nurs 1998;28:737-44.

42. Richardson K, Cert P, MacLeod R, et al. Ever decreasing circles: terminal illness, empowerment and decisionmaking. J Prim Health Care 2010;2:130-5.

43. Wasner M, Longaker C, Fegg M, et al. Effects of spiritual care training for palliative care professionals. Palliat Med 2005;19:99-104.

44. World Health Organization W. Health promotion glossary. Geneva: 1998.

45. Cavalieri TA. Ethical Issues at the end of Life. J Am Osteopath Assoc 2001;101:616-22.

46. Lavoie M, Blondeau D, Picard-Morin J. The autonomy experience of patients in palliative care. J Hosp Palliat Nurs 2011;13:47-53.

47. Carrese JA, Rhodes L. Western bioethics on the Navajo reservation. JAMA 1995;274:826-9.

48. Rego F, Gonçalves F, Moutinho S, et al. The influence of spirituality on decision-making in palliative care outpatients: a cross sectional study. BMC Palliat Care 2020;19:22.

49. Lapine A, Wang-Cheng R, Goldstein M, et al. When cultures clash: physician, patient, and family wishes in truth disclosure for dying patients. J Palliat Med 2001;4:475-80.

50. Long CO. Cultural and spiritual considerations in palliative care. J Pediatr Hematol Oncol 2011;33:S96-101.

51. United States Department of Health and Human

Cite this article as: Rego F, Rego G, Nunes R. Moral agency and spirituality in palliative care. Ann Palliat Med 2020;9(4):2286-2293. doi: 10.21037/apm-19-436
Services, Office of Minority Health. National Standards for Culturally and Linguistically Appropriate Services in Health Care. Rockville: 2001.

52. Rego F, Nunes R. The Spiritual Advocate in Palliative Care. J Palliat Care Med 2016;6:283.

53. Traudt T, Liaschenko J, Peden-McAlpine C. Moral Agency, Moral Imagination, and Moral Community: Antidotes to Moral Distress. J Clin Ethics 2016;27:201-13.

54. Archer M. Structure, agency, and the internal conversation. Cambridge: Cambridge University Press, 2003.

55. Mooney M. Human Agency and Mental Illness. J Crit Realis 2016;15:376-90.

56. Yarborough M. Deciding for others at the end of life: Storytelling and moral agency. J Clin Ethics 2005;16:127-43.

57. Dahlin C, Coyne P, Ferrel B. Advanced practice palliative nursing. New York: Oxford University Press, 2016.

58. Sugarman J. Persons and moral agency. Theory Psychol 2005;15:793-811.

59. Moss E, Dobson K. Psychology, spirituality and end-of-life care: An ethical integration? Can Psychol 2006;47:284-99.

60. Callahan D, Gaylin W. How long a life is enough life? Hastings Cent Rep 2017;47:16-8.

61. Garland-Thomson R. Disability bioethics: From theory to practice. Kennedy Inst Ethics J 2017;27:323-39.

62. Chambaere K, Vander Stichele R, Mortier F, et al. Recent trends in euthanasia and other end-of-life practices in Belgium. N Engl J Med 2015;372:1179-81. 